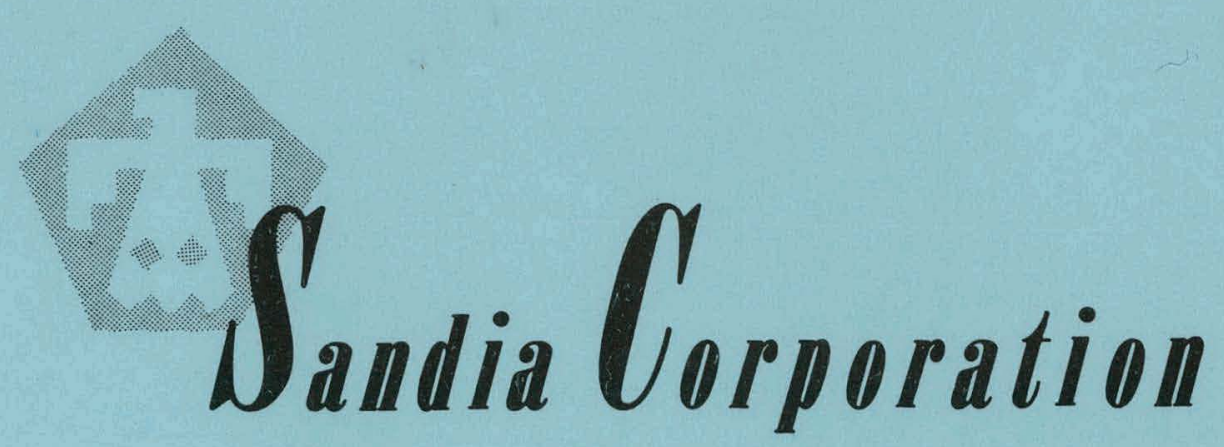

R E P R I N T

\title{
TUBE DESIGN AND CIRCUIT CONSIDERATIONS FOR FAST-HEATING ELECTRONIC SYSTEMS
}

\author{
by \\ K. D. HARDIN
}

JUNE, 1958

WORK PERFORMED UNDER AEC CONTRACT AT-(29-1)-789 


\section{DISCLAIMER}

This report was prepared as an account of work sponsored by an agency of the United States Government. Neither the United States Government nor any agency Thereof, nor any of their employees, makes any warranty, express or implied, or assumes any legal liability or responsibility for the accuracy, completeness, or usefulness of any information, apparatus, product, or process disclosed, or represents that its use would not infringe privately owned rights. Reference herein to any specific commercial product, process, or service by trade name, trademark, manufacturer, or otherwise does not necessarily constitute or imply its endorsement, recommendation, or favoring by the United States Government or any agency thereof. The views and opinions of authors expressed herein do not necessarily state or reflect those of the United States Government or any agency thereof. 


\section{DISCLAIMER}

Portions of this document may be illegible in electronic image products. Images are produced from the best available original document. 
Published in

PROCEEDINGS OF THE 1958

ELECTRONIC COMPONENTS

CONFERENCE - RELIABLE

APPLICATION OF COMPONENT

PARTS 


\section{TUBE DESIGN AND CIRCUIT CONSIDERATIONS \\ FOR FAST-HEATING ELECTRONIC SISTEMS}

by K. D. Hardin

AB STRACT

Fast-heating electronic systems are becoming increasingly important in military applications. Operational requirements in the range of 10 to 12 seconds must be accomplished with a combination of tube and circuit design. Definitions of tube and system operational time are numerous and interrelated so that selection of an appropriate test depends on the circuit application, ease of measurement, and test equipment capabilities. Circuit designs which minimize differences anong tubes will also minimize drift during warm-up so that a stable operating point is reached more quickly. Properties of the vacuum tube classed as detrimental, such as interelectrode leakages, are more critical. in fast operational tubes. Gains in operational time are achieved by: (1) reduction of the heated mass, (2) high cathode activation, and (3) reduction of conduction losses. General design considerations of the heater, cathode, and tube assembly are discussed. Six tube types encompassing subminiatures, miniature, hydrogen thyratron, and power triodes have been developed and produced which function at 10 seconds in a fast operational system. Tube characteristics are given. 


\title{
TUBE DESIGN AND CIRCUIT CONSIDERATIONS FOR FAST-HEATING ELECTRONIC SYSTEMS
}

\author{
INTRODUCTION
}

Fast-heating electronic systems are becoming increasingly important in military applications. Operational requirements in the range of 10 to 12 seconds have become necessary and must be accomplished with a combination of components and circuit design. Many methods of reducing system operational time can be postulated, depending upon use requirements and allowable complexity. A few of the more apparent approaches are listed:

1. Using preheat power, the system is maintained in a "stand-by" concition. Preheat power might be full or reduced, depending on time available from a function signal to actual function time.

2. Overvolting a "cold" system through a programmed cycle to achieve fast operational time. This mathod will reduce the operational time of some receiving tubes to the order of 10 seconcis. But the number of fast-heating starts nust be limited or heater burnout will occur. This method will not reduce operational time of types such as the 2 C39 beyond perhaps 15 seconds.

3. Nominal heater voltage applied to a cold system is the ideal approach. Preheat power and the complication of an overvolting cycle are eliminated.

As usual, the third approach, which is most desirable, is also most difficult to achieve. The first apprcach, probably among the least desirable, i.s most easily accomplished but is not truly a fast-heating system. Discussions in this paper are limited to the third approach.

\section{CIRCUIT TUBE CONSIDERATIONS}

Many definitions of operational time, as applied to the tube itself, are possible; and selection of the proper test depends on the circuit application, ease of measurement, and test equipment capabilities. In deciding upon required system performance at fast operational times, such as 10 seconds, one must keep in mind the fact that many tubes are involved, each operating at 
some defined lower performance level. These considerations make fast operational systems quite impractical unless considerable care is exercised in circuit and tube design. Figure 1 shows stage loss characteristics of a fast-heating subminiature pentode in a transformer-coupled audio circuit. For an IF, audio or video amplifier, 90 per cent of final static plate current at operation time is often suitable, depending upon circuit design. For the particular circuit of Fig. 1, a tube capable of 90 per cent plate current will give 90 per cent of the available circuit gain in 7 seconds. The plate current test is comparatively simple to perform, although the current must be recorded by graph and the acceptability computed. If stability is not so important, only a lower limit -- a minimum plate current at function time -- may be specified. Transconductance has been specified but normally will give no better information than the plate current test and is considerably more involved to measure. Figures 2 and 3 give a comparison of operation time for various circuit conditions for subminiature pentodes. From these data, it may be seen that rapid stabilization of plate current is influenced by bias method and supply voltage scurce impedances or circuit loads. Cathode bias improves warm-up considerably by providing DC negarive feedicack. Signal bypassing of the cathode resistor does not affect warm-up time. Nonaligned grid pentodes, such as data were outained from, will stabilize from 1 to 2 seconds faster if a screen-dropping resistor is employed to provide a more constant current; conversely, warm-up time is impaired by high source impedance in the plate circuit.

Plate current warm-up of a fast-heating triode, Fig. 4, is very similar to the pentode characteristics with one notable exception; a triode will stabilize more quickly with a relatively high impedance plate load. Whereas the pentode requires a low impedance plate circuit. In general, circuit designs which minimize differences among tubes will also minimize drift during warm-up so that a stable operating point is reached more quickiy.

Figure 5 gives a comparison of several circuits classed as fast operational and slow operational, based on the measurenent of tube static characteristics.

Pulse circuits such as blocking oscillators and multivibrators operate the tube in a saturated condition and demand control of peak emission capabili- :. ties rather than small signal characteristics. Operational time of pulse circuits does not bear any necessary or predictable relationship to the tube's DC plate current warm-up. Tubes for such application should be developed to give high peak emission capability, which is stable with life, and improved cathode warm-up time. An appropriate definition of tube operational time for pulse circuit applications would require a minimum peak current or minimum percentage of peak current capability at the function time. Free-running circuits, blocking oscillators, or multivibrators, are most critical to changes of peak emission during warm-up and should be operated with positive bias whenever 
frequency stability is necessary during warm-up. Triggered stages can accept considerably less peak emission stability during warm-up and still give sufficient amplitudes for succeeding stages. In fact, for triggered stages, it has been found that a test for peak emission and a plate current warm-up test will satisfactorily control circuit warm-up time. Peak emission warm-up, as is required for complete definition, is rather involved to perform, presenting equipment and technique diffizulties. Fcr this reason it is advantageous to define characteristics more easily measured.

Balanced circuits should be avoided altogether unless the circuit can be made practically insensitive to wide tube parameter changes, which may involve either peak emission or DC emission. It is very difficult to maintain close balance during warm-up, and for critical circuits, the balance would have to be maintained during life. Circuits of this type sometimes operate with one cathode off ground so that heater-cathode leakage balance during warm-up may also. effect circuit operations.

Gerational time of power circuits, including oscillators, amplifiers, and pulse modulators, are best defined by their power output or pulse output at function time. Simple plate current warm-up tests on the tube would not indicate operational times of these circuits, therefore tube tests are functional, using the actual circuit or cavity. A percentage of final power output at function time or a minimum acceptable poiver output, aither peak or average, is specified. Stability may be improved if it is possible to take advantage of cathode back-heating as quickly as possibie during the turn-on cycle, consistent with cathode life. For example, reduced anode voltage might be applied to an oscillator or gas tube modulator 4 or 5 seconds after application of heater power. Just prior to the required function time, full anode voltage is applied.

Tube specification control of operation time is determined by application requiremeits, circuit design, and ease of measurement. For Class A circuits, such as video, andio and ' $I{ }^{\prime}$ ', a tube specification test-controlling plate current warm-up is indicated. For saturating circuits, such as blocking oscillators and multivibrators, control of peak emission warm-up is essential. Since it is rather difficult to measure relatively fast pulses by oscilloscope observation during warm-up, substitute measurements such as plate current warm-up and stringent control of life-emission capabilities are desirable. Specification warm-up control of power tubes is probably best carried out by functional tests in the actual system to be used. Choice of "percentage" stability requirements or "minimum" requirements will depend strictly on the desired circui.t function. 


\section{TUBE DESIGN}

Properties of the electron tuje classed as detrimental, some of which are controlled by tube specifications, become even more important in the fast operational tube. Some of these detriments are: heater-cathode leakage, warmup-1ife characteristics, insulation of electrodes, heater-life characteristics, and microphonics. Due to higher cathode temperatures normally required for fast warm-up, and mass reductions of all materials in the heater-cathode region, heater-cathode leakage is usually higher and perhaps less stable. Circuits should accommodate higher levels of leakage and should never depend on ' leakage stability for proper system operation. Insulation of electrodes may fall to mininum values during life instead of remaining well above the minimum as in most Mil tubes. Decrimental properties are, for the most part, the price of fast operational time and it will be found that development and refinement of a fast-heating tube type and its specification are largely concerned with control of detrimental properties.

Fast operational impovements in electron tubes are accomplished by: (1) reduction of the heaced mass, (2) high cathoje activation, and (3) reduction of thermal inertia and conduction losses. In the plate current warm-up characteristics of Fig. 6 , time $T_{1}$ is controlled primariiy by the heated mass; viz., heater wire, heater insulation, cathode sleeve, and the oride ccating. Time $\mathrm{T}_{2}$ is a function of cathode activation. A tube hevirg high peak enission will have a fast rise in region $\mathrm{T}_{2}$. Conduction losses through cathcde-mica contact, losies through leads, and cathode tab supports or connections control time $\mathrm{T}_{3}$. Ge:zeral design considerations for fast operational tubes are presented in the following discussicin.

\section{Receiving Types}

Heater design is different among manufacturers, depending on tube mechanical considerations and pernaps on preference by individual manufacturers based on more experience with cns type than another. Coiled heaters, folded, coiledfolded, stagger folded, to menticn a few, were investigated. The most important consiceration in the heater design is probably its insulation. Mass must be held to an absolute minimum consisicnt with environmental and voltage breakdown requiremerts. A pcorly controlled heater-coating process will give a wide range of warm-up times and will account for much of the variability in commercial tubes. Precise control of heater coating is likely to be the finishing touch toward production of fast operational tubes.

The cathode sleeve and its coating constitute a large portion of the heated mass. Reduction of cathode wall thickness has been incorporated in all fast-heating tubes with no significant degradation of mechanical stability, 
although the balance is rather delicate and requires strict control. In some instances it was necessary to design new shapes whose dimensions were more easily controlled and which could be more efficiently supported by the mica spacers. A practical limit in wall reduction is reached when fabrication, handling, and strength become marginal. Weight of the cathode coating is tightly controlled and the coated band maintained precisely between mica spacers and over the heater. Coating composition and cathode base metal help in determining cathode activation, hence time $T_{2}$ of $\mathrm{Fig}$. 6 . Active nickel alloys, such as A-31, containing various amounts of reducing agents are generally used with triple carbonate coatings. The mass of the coating is minimized, consistent with life requirements. Ten-second operational tubes developed for Sandia Corporation have a life of 200 hours.

Intimate thermal contact between heater and cathode must be maintained to provide rapid heat transfer and to reduce relative movement during shock and vibration. Such close contact will also increase heater-cathode leakage. In some mechanical designs it is not necessary to have close fit between heater and cathode. Length of the heater is restricted within the cathode and falls within support micas. Any heater protruding beyond the cathode is heating an unnecessary mass of heater wire. Restricting the heater well within the cathode reduces cathode and temperature so that conduction losses through the mica are minimized. Cathode-mica $f_{i t}$ and contact area determine largely time $\mathrm{T}_{3}$ in Fig. 6. Conduction losses and radiation losses are low during periods $\mathrm{T}_{1}$ and $\mathrm{T}_{2}$, contributing little to warm-up in these regions. Times controlled by total mass $\left(T_{1}\right)$ and cathode activity $\left(T_{2}\right)$ are considerably more effective in reducing and controlling operational time than cathode-mica fit. Contact with the cathode and the snugness with which the cathode is held must be a compromise among vibration noise requirement, cathode warping due to thermal cycling, and operational time.

Materials and processing used in grid and plate construction must be chosen judiciously to reduce the possibility of cathode contamination which destroys peak emission and warm-lip time. Apart from materials considerations, cleanliness, processing, and aging complete the fast operational design. Cathode density, interface condition and surface conditions are affected to a large extent by processing and aging. Processing and aging are generally different among manufacturers and are adjusted to achieve the necessary cathode activity and stability.

\section{Hydrogen Thyratron}

All design considerations of the heater-cathode and its assembly apply as in receiving types. Ceramic spacers are used in place of mica and the cathode is normally supported by metal tabs at the ends. Conduction losses in the end supports may be minimized by using as small a tab as possible. The basic difference between the hydrogen thyratron and vacuum tube is found in the low thermal impedance path through the gas fill, from cathode to bulb. Hydrogen has 
a thermal conductivity of seven to nine times that of air. At zero life, gas pressure is relatively high and maximum thermal losses result. Near the end of life, gas pressure is appreciably lower and conduction losses commensurately reduced. Gas pressure is held as low as possible, consistent with life and warm-up requirements. Heater current may decrease by 10 per cent in 100 hours, indicating the smaller losses and higher cathode temperature:

\section{UHF: Medium-Power Tubes}

Tubes in this category, the $2 \mathrm{C} 39$ and pencil tubes, employ both planar and cylindriczl structures. A structure such as the pencil tube would incorporate the principles discussed for receiving types, with the exception that cathode suppert considerations are modified. Presently avallable pencil tubes exhibit warr-ip times shorter than conventional planar tubes. Planar types, as manufactured, are rather inefficient in regard to heatar power. Operational time improvement of the $2 \mathrm{C} 39$ was accomplished by reductions of total mass, heater redesign, and reduced back losses from the heater. The "hotplate" design which was perfected has proven resistant to vibration and shock and is capable of providing 1 kilowatt of peak power at 10 seconds from a cold start, operated at a pulsed UHF oscillator. Frequency drift in oscillators must be controlled during viarm-up and will be-determined to some extent by cavity design. Drift is smeller if backheating is utilized. Warpage during thermal cycling of the thin inetals used was the primary problen. Techniques for fabrication which produced a strain-free mechanical structuce were devised, allowing the use of thin metals which retained their shape.

\section{TUBE' SPECIFICATIONS}

Fast cperational versions of the 5896, 6111, 5702, 5314, 2C39, and 1258 electronic tubes were developed under Sandia Corporaition contracts. All of these types are either in orototype production or full vroduction. Figure 7

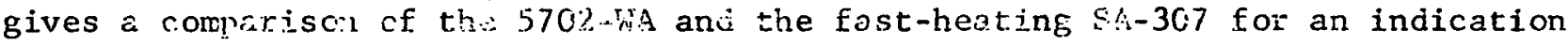
of the improvemen achiaved in cae tyse. Through the crurtesy of the manufacturers, brief specifications onching inportant characteristics, performance, and details of tube design are given. 
$\underline{S A-301}$

Prototype 2C39, developed by Machlett Laboratories

General Characteristics

\begin{tabular}{|c|c|}
\hline Heater voltage & 6.3 volts \\
\hline Heater current & 0.85 ampere \\
\hline Ćathode waṛm-up, minimum & 10 seconds \\
\hline Amplification factor & 80 \\
\hline Transconductance $(70 \mathrm{ma}, 600 \mathrm{v})$ & 16,000 !mhos \\
\hline $\mathrm{c}_{\mathrm{gP}}$ & $2 \mu u f$ \\
\hline $\mathrm{C}_{\mathrm{gl}}$ & $5 \mu \mu f$ \\
\hline $\mathrm{C}_{\mathrm{pk}}, \cdot \max$ mum & $0.04 \mu \mu \mathrm{I}^{\circ}$ \\
\hline Pulse width, maximum & $2 \mu s$ \\
\hline . & 0.001 \\
\hline Peak anode voltage & $3500 \mathrm{v} \mathrm{DC}$ \\
\hline Peak grid bias & -150 volts \\
\hline Frequency, maximum & $3000 \mathrm{mc}$ \\
\hline Peak power at $3000 \mathrm{mc}$ & 1200 wates \\
\hline Operation time ( $90 \%$ pówer output) & 12 seconds \\
\hline Average Iife (place-pulsed os $=i l l a t o r)$ & 200 hours \\
\hline
\end{tabular}

Cathode - 2-mil thick Cathaloy A-31 cap supported by a 0.4-mil cylindrical Kovar foil. Triple carjonate coating. Area about 75 per cent of the iC $39 \mathrm{~A}$. Temperature $830^{\circ} \mathrm{C}$. 
Heater -- A flat spiral coil in close proximity to the back side of the emitter. Shielded from back radiation by a series of three thin radiation shields mounted on a small diameter Kovar post.

\section{$\underline{S A-312(6955)}$}

Prototype 5814-WA, developed by CBS-Hytron

\section{General Characteristics}

Interchangeable with 5814-WA, with following additional characteristics: Operation time ( $80 \%$ plate current) 10 seconds

Peak cathode current

Maximum pulse width

Average grid current

Peak positive grid voltage

Heater-cathode leakage (100 volts)

Pulse life ( 2 a peak, $t p=1.5 \mu s$ )

Static life (5814-WA life test)
2 amperes

10 is

5 mAdc

200 volts

$10 \mu \mathrm{a}$

200 hours

200 hours

\section{Design Features}

Cathode -- Cylindrical Inconel 220, coated with triple carbonate. Wa1l thickness 0.0025 inch. Temperature $825^{\circ} \mathrm{C}$.

Heater - - Folded eight-leg configuration. Controlled, thin coating especially critical at bends. Centered exactly beneath coated band of the cathode.

Other -- Alclad plates, 6 per cent gold-plated moly grids, carbonized bulb, multivibrator aging.

$\underline{S A-311}$

Prototype 5896, developed by Sylvania Electric 


\section{General Characteristics}

Equivalent to the 5896 with the following exceptions and additions:
Heater current
$400 \mathrm{~mA}$
Operation time ( $85 \%$ emission)
10 seconds
Heater-cathode leakage
$40 \mu \mathrm{a}$
Average life
200 hours

\section{Design Features}

Cathode -- Cylindrical, Sylvania N4 nickel. Wall thickness 0.00225 inch. Triple carbonate coating 0.0035 inch thick. Temperature $800^{\circ} \mathrm{C}$. Heater - Straight coils, series connected. Insulation thickness

0.0035 inch. Coils individually cataphoretically coated.

$\underline{S A-310}$

Prototype 6111, developed by Raytheon Manufacturing Company

\section{General Characteristics}

Equivalent to the 6111 with the following additions:

$\begin{array}{ll}\text { Operation time }(90 \% \text { plate current) } & 10 \text { seconds } \\ \text { Peak cathode current } & 1 \text { ampere } \\ \text { Peak positive grid voltage } & 100 \text { volts } \\ \text { Average life }(0.8 \text { a section peak } & \\ \text { tp }=1 \mu \mathrm{s}) & 200 \text { hours } \\ \text { Average } 1 \text { ife }(6111 \text { static life) } & 200 \text { hours }\end{array}$

\section{Design Features}

Cathode -- Oval-shaped Inconel 220. Wall thickness 0.002 inch. Triple carbonate coating. Temperature $750^{\circ} \mathrm{C}$. 
Heater - Folded coils, connected in series. Very pure coating applied in extremely thin layer.

$\underline{\mathrm{SA}-303}$

Prototype 1258 hydrogen thyratron, developed by Chatham Electronics Division of Tungsol.

\section{General Characteristics}

Equivalent to the 1258 with the following exceptions:

$\begin{array}{ll}\text { Heater current } & 1.85 \text { amperes } \\ \text { Cathode heating time, minimum } & 5 \text { seconds } \\ \text { Operation time ( } 35 \% \text { peak emission) } & 10 \text { seconds } \\ \text { DC anode voltage } & 1200 \mathrm{v} \mathrm{DC} \\ \text { Average life }(\text { epy } \times \text { PRR } \times \text { ib }=0.05 & 200 \text { hours } \\ \left.\times 10^{9}\right)\end{array}$

\section{Design Features}

Cathode -- Cylindrical weld-drawn P-50 nickel coated with a pulse emission coating covering 0.170 in. ${ }^{2}$ of cathode area. Quiescent temperature $750^{\circ} \mathrm{C}$. Wall thickness 0.0022 inch. Welded tab support for cathode top and bottom.

Heater -- Double helix, 0.007 inch Tungston wire. Coating cataphoretically applied to 0.0014 inch thick. OD of coated helix is 0.001 inch larger than cathode ID to provide intimate thermal contact.

$\underline{\mathrm{SA}-307}$

Prototype 5702-WA, developed by Raytheon Manufacturing Company

Genera1 Characteristics

Equivalent to the 5702 with following exceptions and additions:

Operation time ( $90 \%$ plate current) 10 seconds 


\author{
Insulation of electrodes (end of life) 10 megohms \\ Average life 200 hours
}

Design Features

Cathode -- Oval-shaped Incone1 220. Wall thickness 0.002 inch. Triple carbonate coating. Temperature $750^{\circ} \mathrm{C}$.

Heater -- Folded coil. Very pure coating applied in an extremely thin layer.

A11 tubes are required to meet the following environmental conditions:

Mechanical Shock:

18 inpacts, $100 \mathrm{~g}^{\prime} \mathrm{s}, 30 \mathrm{milliseconds}$

Vibiation:

Six-hour total: $0.036 \mathrm{P}-\mathrm{P}$ displacement, 10 to $75 \mathrm{cps}$

10-g acceleration, 75 to $500 \mathrm{cps}$. Three hours cycled, three hours at noise resonance.

Temperature:

$-65^{\circ} \mathrm{C}$ to $100^{\circ} \mathrm{C}$ ambient

Iife:

200-hour test. Average 1ife, 160 hours.

\title{
SUMMARY
}

The design of a fast-heating electronic system must be a combination of circuitry to give electronila tures the most favorable corditions for rapid stabilization and of electron trbe themal design. Tube specification control and the definiticns of tube cperation tine are determined by the circuit function; a digital system or circuit would utilize minimum limits on tube warm-up characteristics, while an aralog systein must require a certain stability for pzoper function. Trioe designs, to achieve fast operation time, are sccomplishej by development of highly activaced cathcdes, reduction of thermal inertia in the heater-cathode structure, and very stringent controls of all processes and rotesances. Six tube types were developed under cognizance of Sandia Corporation which feature operation time of 10 seconds, from a cold start, for use in a fast-heating electronic system. 


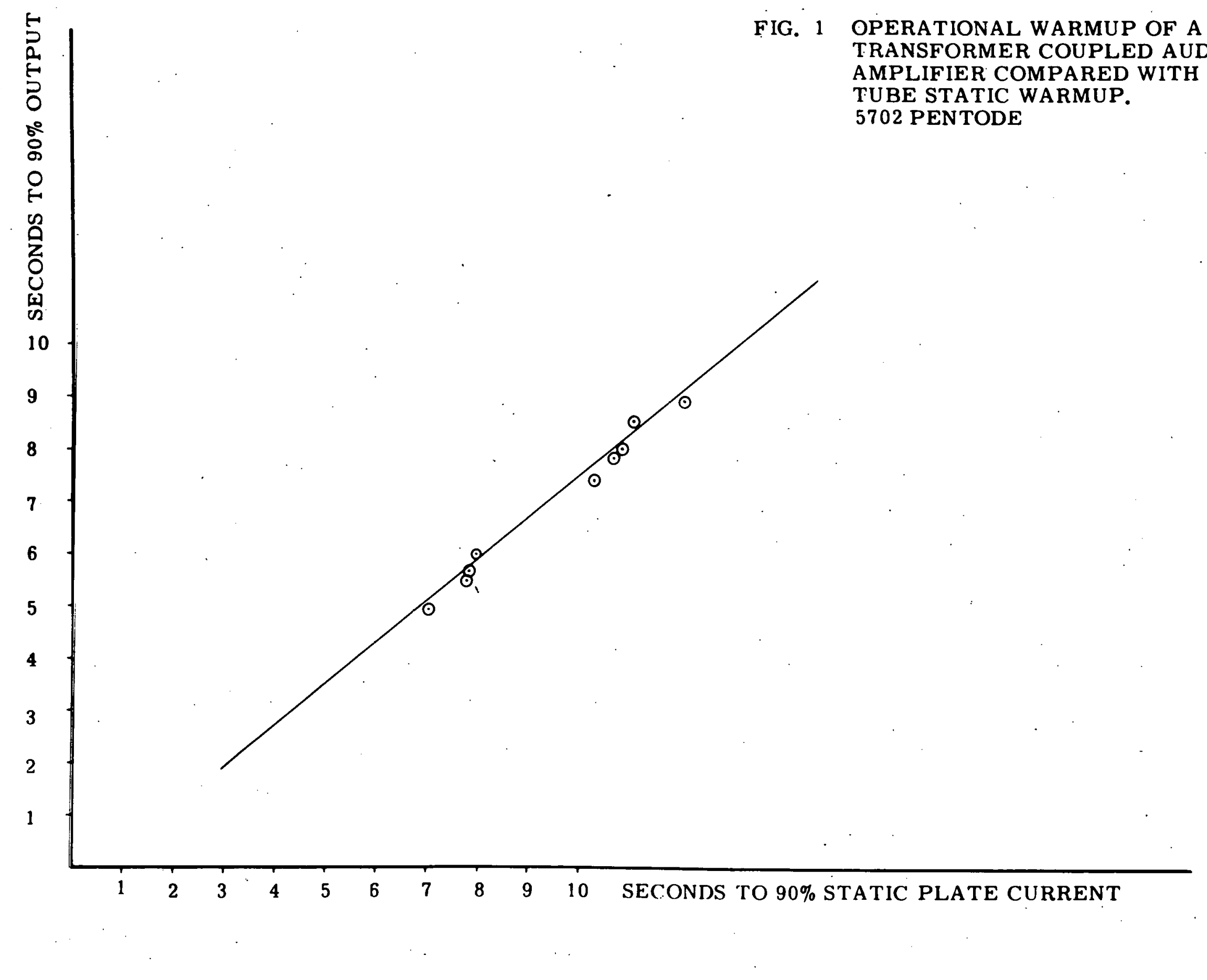


FIG. 2 TYPICAL WARMUP CHARACTERISTICS FOR THE FAST HEATING SA-307 SHOWING THE EFFECTS OF BLAS METHOD AND HEATER

VOLTAGE SOURCE IMPEDANCE.

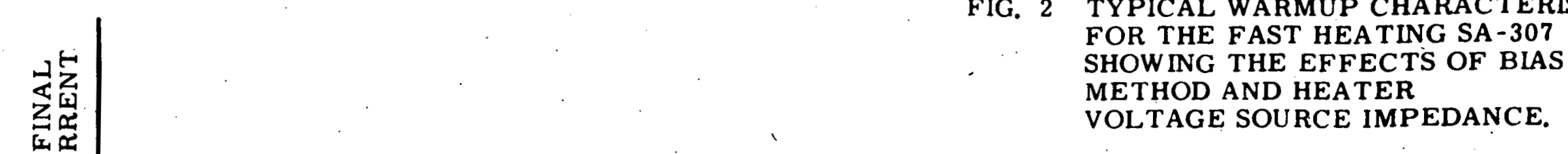

ZU

(기니

U⿺辶一兀

â,

100

90

80

70

60

50

40

30

20

10

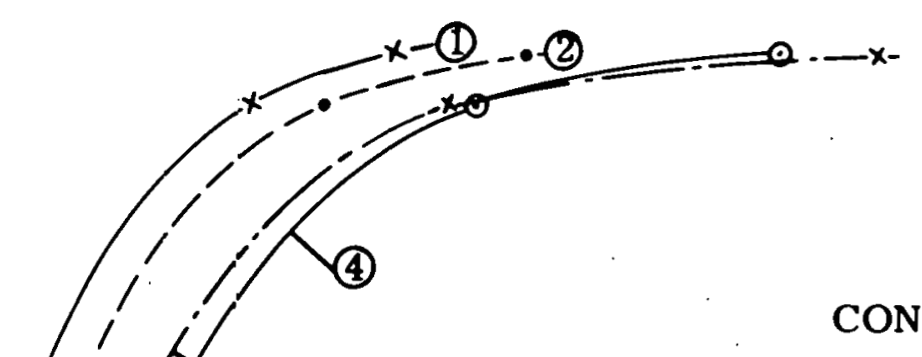

CONDITIONS:

$E b=120=K, E_{c_{2}}=120=K$

(1) $R_{K}=200, R_{H}=.25 \Omega$

(2) $R_{K}=20,0, R_{H}=4.0 \Omega$

(3) $E_{c 1}=1.75, R_{H}=.25 \Omega$

(4) $E_{c 1}=1.75, R_{H}=4.0 \Omega$ 
FIG. 3 WARMUP CHARACTERISTICS FOR THE FAS'T HEA TING SA-307 SHOWING THE EFFECT OF SCREEN \& PLATE VOLTAGE SOURC.E IMPEDANCE.

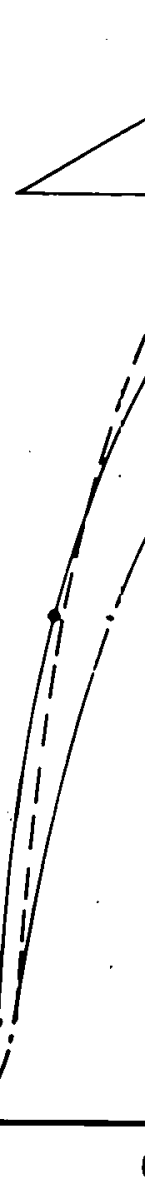

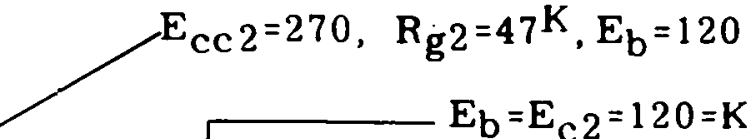
$-E_{c 2}=120=K, E_{b b}=240, R_{p}=10^{K}$

CONDITIONS:

$E_{F}=6.3, R_{H}=25 \Omega$

$R_{K}=200 \Omega$

$\leftleftarrows$ 


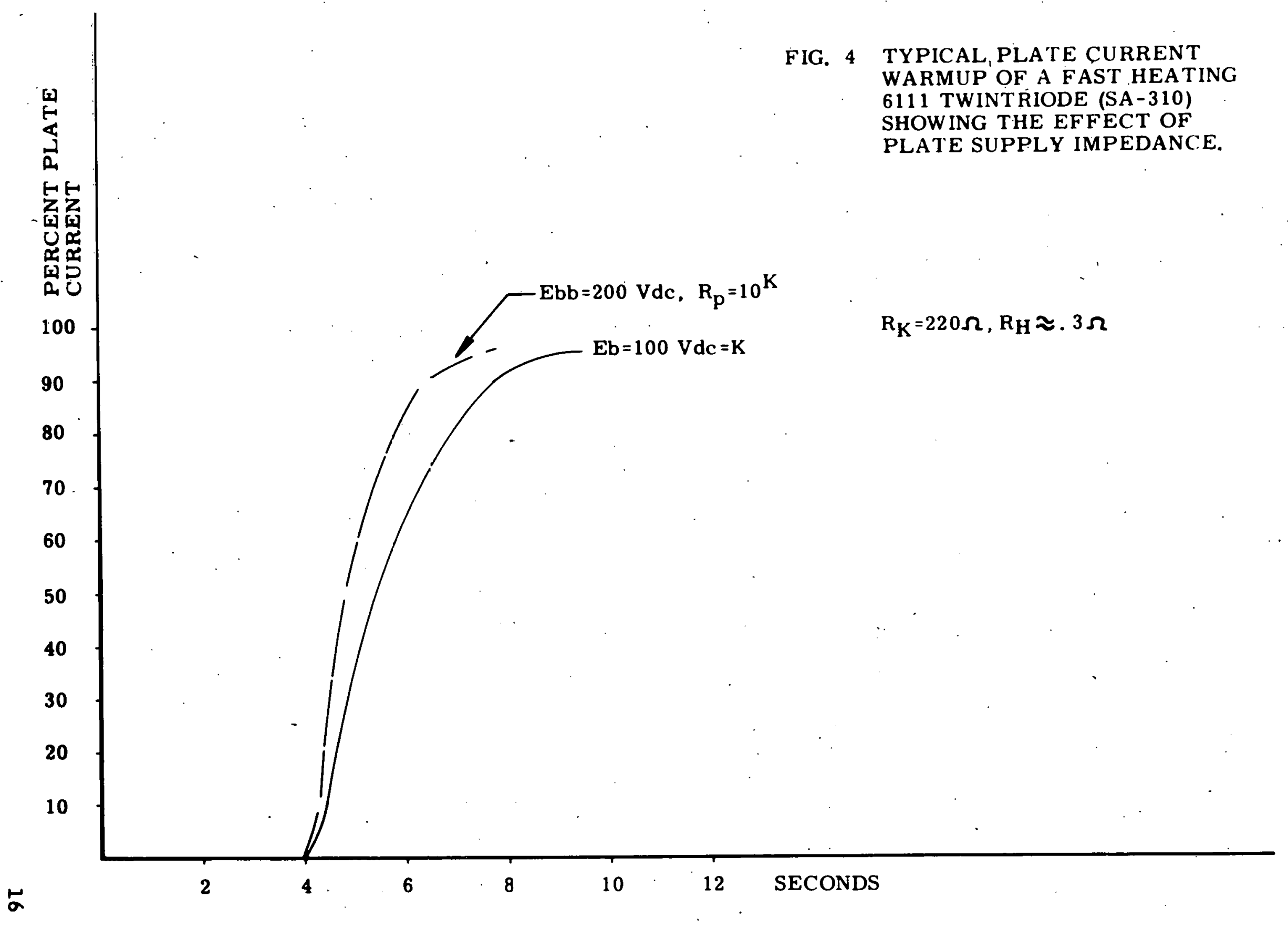


FIG. 5

FAST CIRCUITS
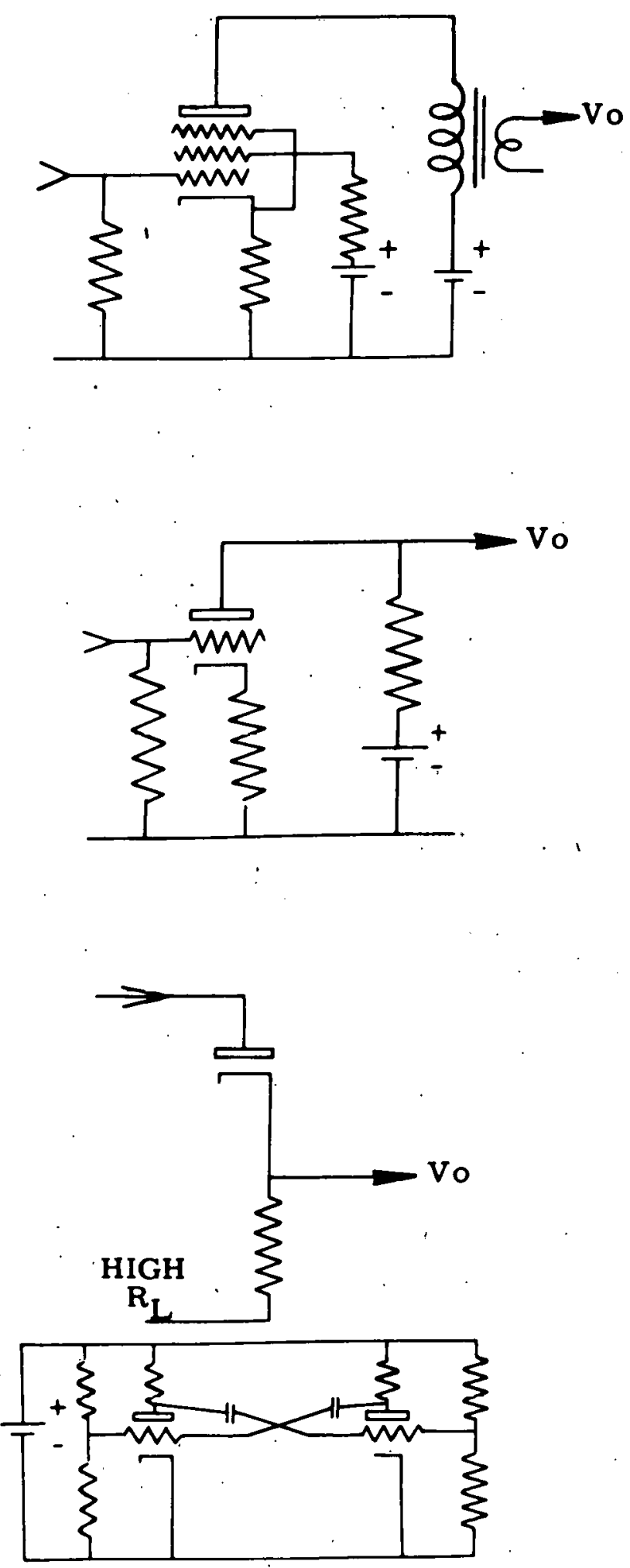

SLOW CIRCUITS
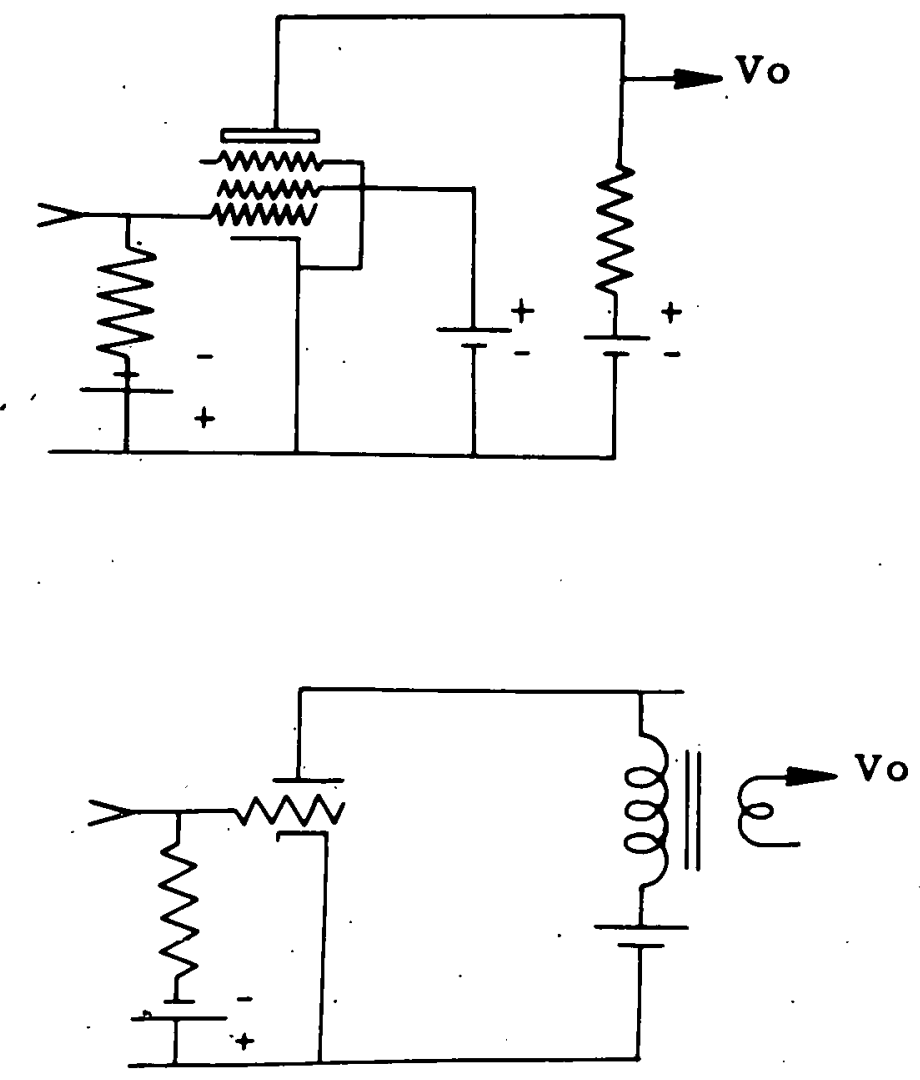

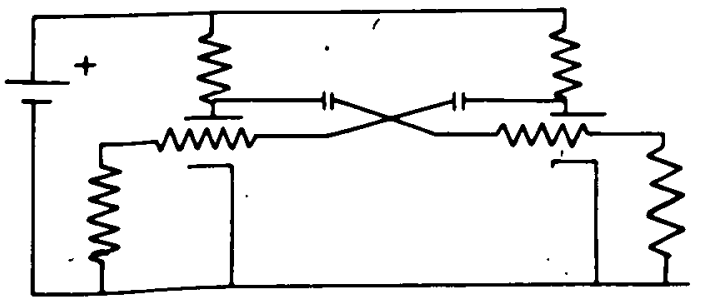




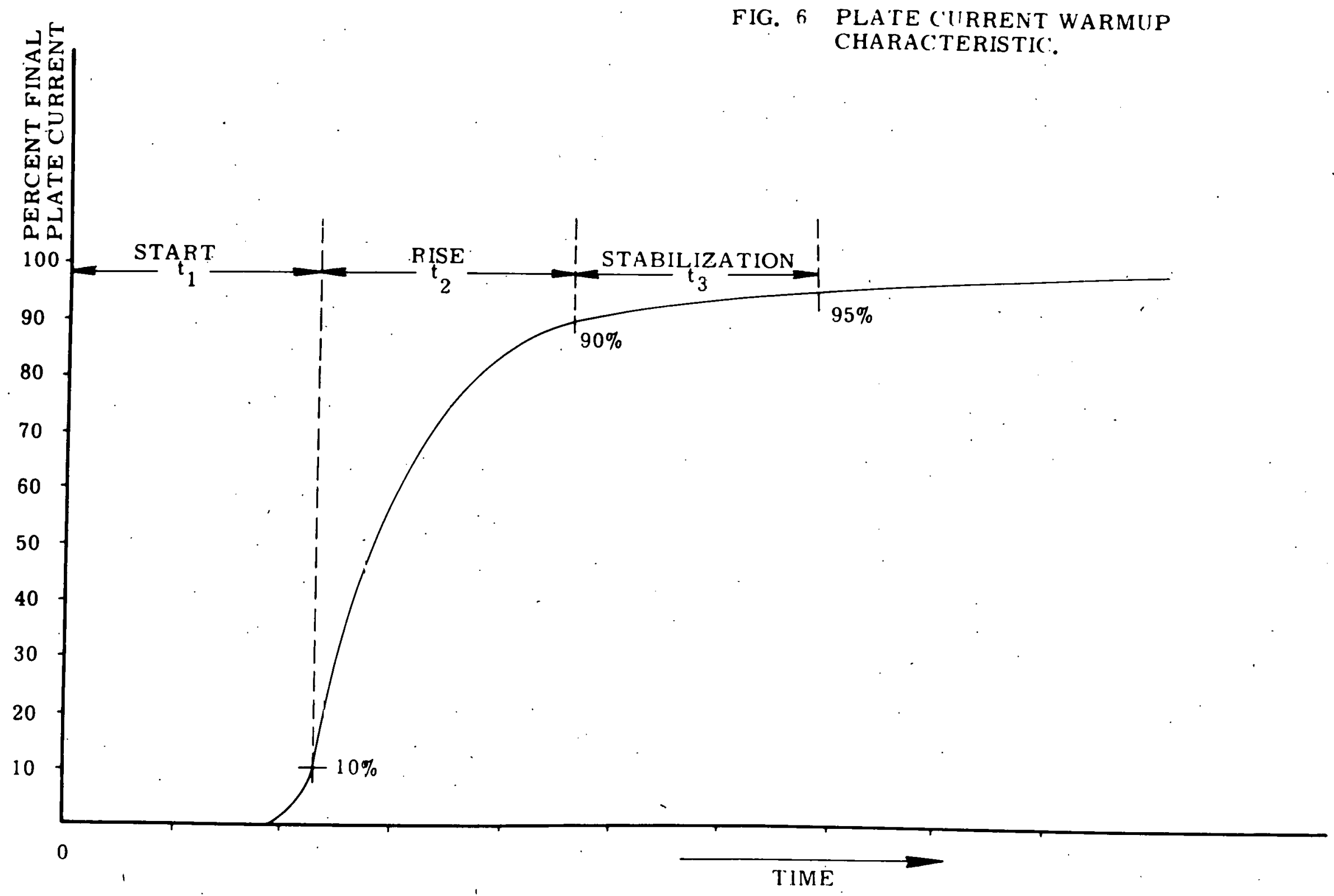


FIG. 7 COMPARISON OF THE 5702' WARMUP CHARACTERISTIC WITH A FAST HEATING SA-307 FOR TWO CIRCUIT CONDITIONS.

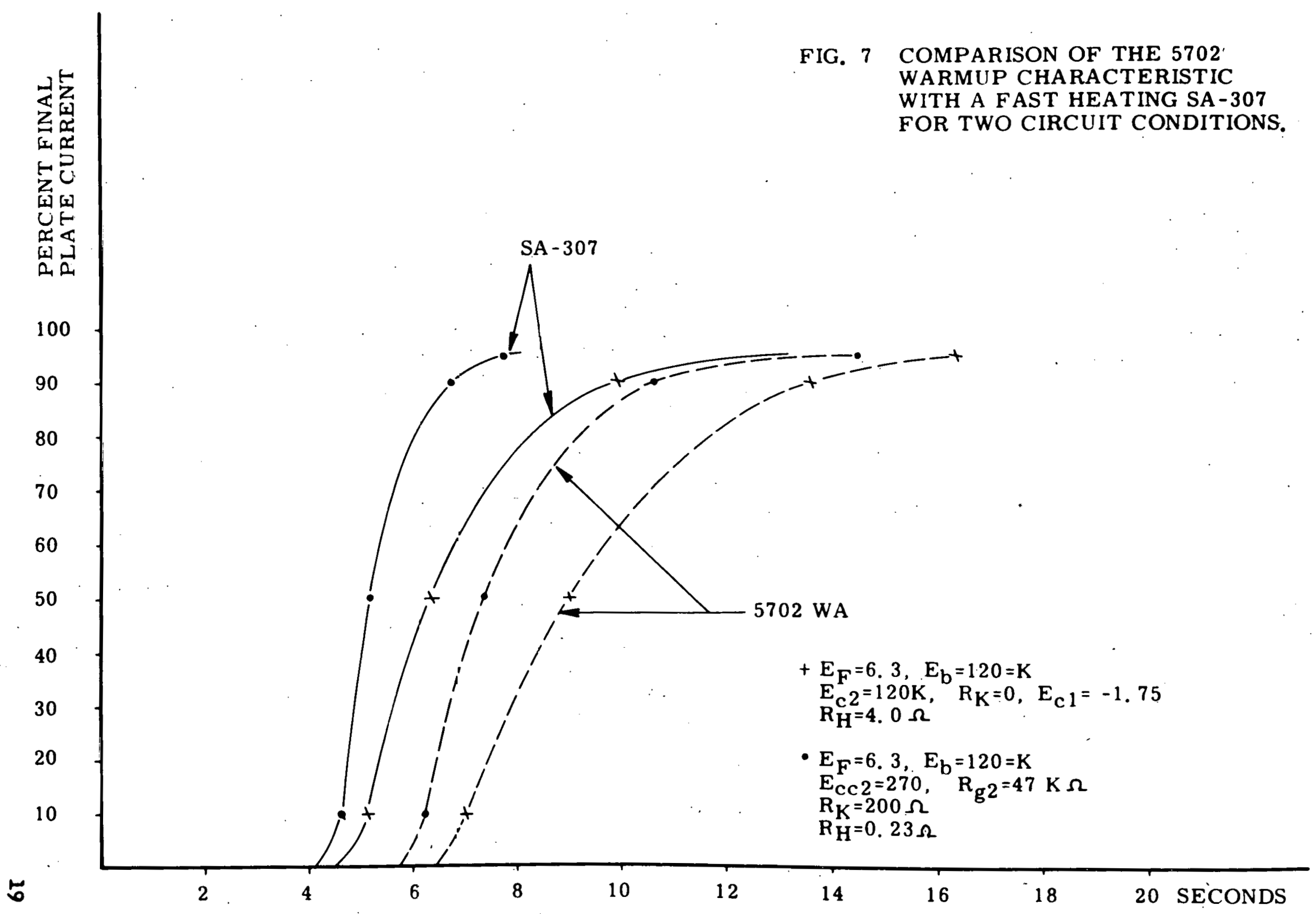


Issued by

Technical Information Division

Sandia Corporation

Albuquerque, New Mexico

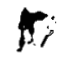

\$ 